\title{
A Critical Evaluation of the Single-Use Policy of Endodontic Instruments
}

\author{
Reem AlYamoor ${ }^{1}$, Stefan V. Stefanescu ${ }^{2 *}$, Haider Al-Saffar ${ }^{2}$ and Mihai Calin Chirila ${ }^{3}$ \\ ${ }^{1}$ My Dentist, Stone Dental Practice, Stone, ST158AW, UK \\ ${ }^{2}$ My Dentist, Europa House, Europa Trading Estate, Stoneclough Road, Manchester M26,1GG, UK \\ ${ }^{3}$ Refresh Dent, 86-90 Oasului Street, Cluj-Napoca, Romania \\ *Corresponding author: Stefan Vasile Stefanescu, 193A WarringtoniRd, Whiston, L35 5AF, Merseyside, UK; Tel: i+447712702307
}

Received: July 17, 2020; Accepted: July 27, 2020; Published: August 04, 2020

\begin{abstract}
Endodontic treatments involve accessing a sterile or non-sterile pulp chamber and root canal content, following an inflammation of the pulp or bacterial colonization of the pulp chamber and root canals, as a septic complication of decay. For this purpose, stainless steel instruments were developed in the last century and Ni-Ti files more recently, serving for different purposes during different procedures and manoeuvres having the unique goal to clean and seal the root canal. For this purpose stainless steel and more recently, nickel-titanium (Ni-Ti) instruments have been developed. These instruments not only increased the speed of the treatment but also managed to assure a proper shape of the canal preparation and subsequently, of the canal filling. Being so useful, reliable, resistant, and ultimately, not cheap, the initially single-use instruments got to be reused by a wide number of practitioners. The present review critically evaluates the single-use policy of these instruments, debating on aspects like cross-infection, mechanical aspects, sterilization protocols and its effect in these instruments, highlighting what is known at the moment about it.
\end{abstract}

Keywords: Endodontic, Policy, Prions, Review, Root-canal, Single-use

\section{Introduction}

Endodontic treatments involve accessing a sterile or non-sterile pulp chamber and root canal content, following an inflammation of the pulp or bacterial colonization of the pulp chamber and root canals, as a septic complication of decay. For this purpose, stainless steel instruments were developed in the last century and $\mathrm{Ni}$ - $\mathrm{Ti}$ files more recently, serving for different purposes during different procedures and manoeuvres having the unique goal to clean and seal the root canal respecting the biologic and mechanical principles stated by Schilder [1]. Newer (Ni-Ti) files not only increased the speed of the treatment but also managed to assure a proper shape of the canal preparation and subsequently, of the canal filling. Being so useful, reliable, resistant, and ultimately, not cheap, the initially single-use instruments got to be reused by a wide number of practitioners for at least 5 times, with great success, being assured by the manufacturers that both files and the tooth are safe. There are reports of file reuse on 12 [2] or 24 [3] extracted roots having medium curvature.

Worldwide legislations are not prohibiting the reuse nor imposing the single-use, with very few exceptions. Medicine and Health Care Regulatory Agency in the United Kingdom have considered that an instrument used in the root canal should not be reused on multiple patients, not even on the same patient on a later occasion, and hence should be discarded [4]. The Department of Health has critically evaluated the importance of a singleuse endodontic instrument during dental treatment, to supply the patients with a safe and infection controlled environment [5]. There was obvious evidence that showed the risks associated with the reuse of endodontic files, including secondary Transmissible Spongiform Encephalopathy disease (TSEs) and improper debris control [6]. But besides these aspects, it has also been shown that the use of endodontic file decontamination and sterilization methods can play a role in the development of various risks such as file fracture.

In modern dentistry, all clinicians should consider infection control maintenance, as it cannot be dismissed [7]. Microorganism has an obvious rule for developing infected necrotic pulp tissue which was isolated from infected root canals [8]. Fusobacterium nucleatum, Porphyromonas Gingivalis, and Streptococcus mutants are the most common bacteria that were isolated from infected root canals [7]. Van Eldik [7] in his research done on stainless steel and NI-TI files, demonstrated the effect of thermal steam sterilisation and mechanical cleaning techniques on the microbial elimination. They concluded that there were no bacteria detected on new files or following steam sterilisation. On the other hand, the ultrasonic bath eliminated the majority but not all of the bacteria. Assaf, Mellor, and Qualtrough [9] illustrated that mechanically cleaning endodontic files by using washer-disinfectant treatment can lead to incomplete organic debris removal from endodontic files's surfaces.

\section{Aspects Related to Prion Disease}

The prion proteins were discovered in 1982 as a fatal neurodegenerative protein with different groups like $\operatorname{PrP}$. This can 
cause scrape veterinary diseases and veterinary Creutzfeld-Jacob Disease (vCJD) in humans [6,10]. Creutzfeld-Jacob Disease can be transmitted by direct blood contact or transfusion [10]. The Prion protein has a high resistance to many disinfectant and sterilisation techniques such as chemical, thermal, ionizing radiation, and ultraviolet decontamination resistance, with a high binding capacity to metal surfaces, compromising the sterilisation process especially in dried contaminated tissue on metal or glass surfaces $[6,11,12]$.

The prion disease accumulates in the lymphoreticular tissue and the nervous system. Early diagnosis of human prion disease can be detected by lymphoreticular biopsy of tonsils, spleen, and lymph nodes [13]. Few studies have linked re-used endodontic files with transmissible spongiform encephalopathy (TSEs) which is a group of brain and nervous system diseases in humans and animals that can develop in the presence of prion prusiner protein. Although, no obvious research stated that Creutzfeldt-Jakob Disease (vCJD) has been transferred to humans during dental treatment [6] one of prion's possible way of transmission from the brain to the mouth tissues and vice versa is assumed to be by means of prion protein accumulation in the trigeminal ganglia of patients with this disease [14]. There were four cases reported of possible transmission of CJD infection by means of blood transfusions but no evidence so far that CJD is contagious either by normal or sexual contact $[15,16]$. Even so, before seeking any endodontic treatment, it is mandatory to obtain from all patients appropriate family and medical history as well as sterilise the endodontic files for optimal infection control $[11,17]$.

Currently, in the United Kingdom, The Health Department has considered root canal treatment files as single-used instruments and should be segregated immediately after clinical use $[4,18]$. Dental instruments (except files) used on patients with or "at increased risk" of CJD can be handled in the same way as those used in any other low-risk surgery, can be reprocessed according to best practice and returned to use [4]. Other instrument types for which a reliable cleaning regime is not available should also be considered singleuse types. Although the Department of Health UK guidelines does not recommend any special protocols for prion decontamination, an improved cleaning process along with multiple cycles of vacuum steam sterilization procedure should be followed [19].

\section{Aspects Related to Sterilization and Its Effect on the Rotary Instruments}

Endodontic Nickel-titanium (Ni-Ti) files were used for root canal treatment for more than 25 years because of their flexibility, flexural, and torsional resistance [20]. Many studies have been done observing the effects of sterilization on these instruments' properties. Some of them found no significant effects [21]. Condorelli et al. [22] identified the same type of increased resistance to cyclic fatigue, although the thermal applications did not alter instrument surface morphology but resulted in significant changes in the instrument bulk with the appearance of an R-phase and improved fatigue resistance. Sonntag and Peters [6] found a better fatigue life after five cycles of dry-heat sterilization at $180^{\circ} \mathrm{C}$.

Conversely, many studies found sterilization negatively impacting the file's life span, features, characteristics, and properties [23-27]. Autoclaving and re-using of the endodontic files more than three times can lead to a change in the physical properties of the alloy, like blunt cutting edge, pitting chipping, and fritting [28]. Another study has confirmed that multiple or a single autoclave cycle of endodontic files can result in the file's surface corrosion with a reduction of flexural and torsional fatigue resistance [29].

Most of the studies proved that cyclic fatigue resistance decreased and led to a high chance of file fracture especially when the root canal curvature increased $[25,26,27]$.

\section{Aspects Related to Corrosion and Its Effect on the Rotary Instruments}

It is well documented that bacterial infection of the root canal is the primary cause of apical periodontitis $[8,30,31]$. The apical periodontitis is the result of bacterial invasion and consecutive colonization of the entire endodontic system. Thus treatment has to be directed toward the elimination of micro-organisms from within the endodontic system and prevention of re-infection [31]. Therefore, chemomechanical preparation of the root canal, which is a combination of mechanical instrumentation and antibacterial irrigation, is the critical stage in canal disinfection. These irrigants are also used to suspend and rinse away debris created during instrumentation, dissolve the organic tissue, or as a lubricant for instruments, to remove the smear layer.

Since there is obvious evidence that autoclave and chemical sterilisation technique goes the best hand in hand for re-used dental files and burs, causing a 100\% microbial elimination [32], files corrosion has to be assessed as well. Rutala and Weber [33] demonstrated the proper decontamination steps of endodontic files with chemical agents by using Sodium hydroxide $(\mathrm{NaOH})$ solution for 24 hours, 1 hour respectively, then using guanidine thiocyanate for 24 hours, 1 hour and 15 minutes respectively. Later on, they sterilised files by autoclave at $134^{\circ} \mathrm{C}$ for 18 minutes. Also, a short decontamination process by immersing the files with chlorhexidine solution, manual cleaning then submersion in $1 \% \mathrm{NaOCl}$ solution, ultrasonic cleaning, and finally steam sterilising by autoclave was advocated [33].

It was shown that during extended periods in $\mathrm{NaOCl}$ solutions, corrosion may be enhanced [34] or minimized depending on the $\mathrm{pH}$ of the environment [35]. Though the impact of $\mathrm{NaOCl}$ did not show any difference in the cutting efficiency or resistance to fracture of $\mathrm{Ni}-\mathrm{Ti}$ instruments [36,37], it did result in reduced resistance to cyclic fatigue $[38,39]$ and the presence of corrosion [6]. Further studies in which the percentage of $\mathrm{NaOCl}$ was low (1\%) showed no major impact on $\mathrm{Ni}$-Ti instruments; however, those that studied the impact of a $5 \%$ solution noted significant changes [40]. Some studies showed that a sterilization cycle along with immersion in $\mathrm{NaOCl}$ did not result in any substantial instrument changes [41]. In Catania University of Italy [42], the authors conducted a study to show the effect of treating files with either $5 \% \mathrm{NaOCl}$, sterilisation or heat-sterilized Ni-Ti rotary files or both and whether there was an effect on the cyclic fatigue resistance [42] or not. They have collected 210 files, which were twisted files (TF) (SybronEndo, Orange, CA) and Hyflex CM (Coltene Whaledent, 
Cuyahoga Falls, OH) files size 25/0.06. They were divided into 7 groups, the first group was not sterilised by autoclave or immersed with $\mathrm{NaOCl}$, group 2 and 3 did not autoclave files, but immersed them with $5 \%$ of $\mathrm{NaOCl}$ once and three times respectively, Group 4 and 5 files were only autoclaved once and three times without immersion into $5 \% \mathrm{NaOCl}$, while group 6 and 7 treated with both $5 \% \mathrm{NaOCl}$ and autoclave once and three times respectively. The files were then tested using field-emission scanning electron microscopy and $\mathrm{x}$-ray energy-dispersive spectrometric (EDS) analysis to determine file surface defects and fractures. TF showed lower fatigue resistance than $\mathrm{CM}$ files group after 3 times autoclave sterilisation. EDS showed that immersion of Hyflex CM files in $5 \% \mathrm{NaOCl}$ developed an oxide-rich layer on the file's external surfaces. EDS also showed that repeatedly treating files with sterilisation or chemical cycles $(\mathrm{NaOCl} 5 \%)$ has no morphological changes on the CM files surface apart from TF files that have demonstrated low flexural resistance with an increased chance of fracture.

\section{Aspects Related to Mechanical Failure}

"A material will fail by torsion when the ultimate shear strength is exceeded" according to Walia [43]. Studies proved that an instrument will fracture if its ultimate strength is exceeded [44-47] or if a fracture line has extended to such an extent that the remaining intact crosssection of the file is unable to bear the functional load [48] thus complicating the whole treatment. Scanning electron microscopy observations proved that instruments deteriorate while in use, and develop defects and cracks on their surfaces inducing fracture propagation $[3,28,49,50]$. Although new instruments can fracture at their first canal use, those that are used for three or more canals may have a higher susceptibility for fracture. Gambarini [51] demonstrated that the used instruments had a lower resistance to fracture than new ones.

There are 2 possible mechanisms of fracture described in the literature:

a) Torsional or sheer fatigue. The fractographic image of shear failure is very spectacular, showing the plastic deformation of the flutes adjacent to the fracture site, along with concentric circular markings at the periphery with a 'fibrous' appearance in the center. The fibrous region corresponds to the microscopic dimples in high power, while the circular markings are due to abrasion of the opposing surfaces on either side of the fracture [52-56].

b) Cyclic fatigue. The term 'cyclic fatigue' has been used to describe the breakage of Ni-Ti instruments after continuous rotation in a curved canal. An instrument rotating with curvature is effectively subjected to a completely reversed cyclic loading at its surface. A form of fatigue loading, such rotational bending has been implicated as the reason for breakage of some $44-91 \%$ of $\mathrm{Ni}-\mathrm{Ti}$ engine-files fractured clinically $[52,53,55,56]$.

It has been emphasised that there is no fracture caused by purely one of the mechanisms, there is always a combined effect of the two. Frequent reuse of endodontic files can lead to change in their physical properties and cause file fracture particularly in curved and calcified canals [27]. Some reports found that the incidence of separation of unused rotary $\mathrm{Ni}$-Ti files is about $1 \%$ [57-62] while distortion was noticed to occur in up to $60 \%$ of the instruments used [63], but it is estimated that the incidence of instrument fracture in instruments used multiple times varies between $0.39 \%$ and $21 \%[44,46,47,50,64$ 66]. There are also reports that Ni-Ti engine-files may fracture without any warning signs $[53,54,57]$.

\section{Conclusion}

For the high standard of dental care, it is mandatory to segregate single-use endodontic instruments like files and reamers according to the department of health policy nevertheless, steam sterilisation is essential to instruments that cannot be segregated like endodontic rulers, dental hand instruments, rubber dam clamps or handpieces. Furthermore, proper infection control and to obtain a healthy environment for patients and dental staff. Ni-Ti files are the most commonly used endodontic files in dentistry as they have a good shape memory with low risk of fatigue, in addition to that they are safe, easy to use, and discard [22]. The dental clinicians should have full knowledge and appropriate diagnosis about prion disease, its way of transmission, proper decontamination, and how to prevent it even if there is no clear confirmation of its transmition by means of dental procedures. The high binding capacity of Prion protein to dental metal instrument surfaces can render disinfection very difficult and challenging, hence sterilisation methods can be a very big task to perform. Judging by mechanical point of view, the reuse of a rotary file, no matter the alloy it's been made of and the stress it is capable to bare, is risky and might jeopardise the treatment itself along with its outcome. Using rotary files as single-use instruments can lead to increased clinical confidence and a positive outcome of dental treatment.

\section{Reference}

1. Schilder H (1974) Cleaning and shaping the root canal. Dental Clinics of North America 18: 269-296. [crossref]

2. Stefanescu T, Galuscan A, Tudoran LB, Monea MD, Jumanca D (2016-a) Environmental effect on Ni-Ti rotary files: Steam sterilization \& corrosion. A SEM study Rev Chim 67: 2114-18

3. Stefanescu T, Antoniac IV, Popovici RA, Galuscan A, Tirca T (2016-b) Ni-Ti rotary instrument fracture analysis after clinical use. Structure changes in used instruments. EEMJ 15: 981-88

4. Department of Health (2013) Decontamination Health Technical Memorandum 0105: Decontamination in primary care dental practices.

5. Cockcroft B (2007) Government advises single use of endodontic instruments. Department of Health. 202: 442

6. Sonntag D, Peters OA (2007) Effect of Prion Decontamination Protocols on NickelTitanium Rotary Surfaces. Journal of Endodontics 33: 442-446. [crossref]

7. Eldik D Van, Zilm P, Rogers A, Marin P (2008) Microbiological evaluation of endodontic files after cleaning and steam sterilization procedures. Australian Dental Journal 49: 122-127. [crossref]

8. Kakehashi S, Stanley HR, Fitzgerald RJ (1965) Oral Surgery Oral Medicine Oral Pathology 20: 340-349

9. Assaf, Mellor, \& Qualtrough (2018) Cyclic Fatigue Resistance of Heat-treated Nickel-titanium Instruments after Immersion in Sodium Hypochlorite and/or Sterilization. Journal of Endodontic 44: 648-653. [crossref] 
10. Knight R (2017) Progress in Molecular Biology and translational Science 150: 293318

11. Jayanthi P, Thomas P, Bindhu PR, Krishnapillai R (2013) Prion diseases in humans: Oral and dental implications. North American Journal of Medical Sciences 5: 399403

12. Walker JT, Dickinson J, Sutton JM, Raven NDH, Marsh PD (2007) Cleanability of dental instruments - Implications of residual protein and risks from CreutzfeldtJakob disease. British Dental Journal 203: 395-401. [crossref]

13. Porter SR (2002) Prions and dentistry. Journal of the Royal Society of Medicine 95: 178-181.

14. Guiroy DC, Shankar SK, Gibbs J, Messenheimer JA, Das S et al. (1989) Neuronal degeneration and neurofilament accumulation in the trigeminal ganglia in CreutzfedtJakob disease. Ann Neurol 25:102-106. [crossref]

15. Ingrosso L, Pisani F, Pocchiari M (1999) Transmission of the $263 \mathrm{~K}$ scrapie strain by the dental route. J Gen Virol 80: 3043-3047. [crossref]

16. Wells GAH, Hawkins SAC, Green RB (1998) Preliminary observations on the pathogenesis of experimental bovine spongiform encephalopathy (BSE): an update. Vet Rec 142: 103-106. [crossref]

17. Hancock CO, Lambert PA, Dusseau JV (2013) Sterilization Processes. In: Fraise, AP, Maillard, JY, Sattar, S, eds. Russell, Hugo and Ayliffe's Principles and Practice of Disinfection, Preservation and Sterilization. 5: 277-370.

18. Sonntag D, Martin E, Raab WHM (2016) Representative survey on the reprocessing of endodontic instruments in Germany. British Dental Journal 220: 465-469. [crossref]

19. Department of Health, UK (2009) Commissioning and Systems Management. Health Technical Memorandum 01-05: Decontamination in primary care dental practices. London, UK: Department of Health.

20. Zhou H, Peng B, Zheng Y (2013) An overview of the mechanical properties of nickel-titanium endodontic instruments. Endodontic Topics 29: 42-54.

21. Khabiri M, Ebrahimi M, Saei MR (2017) The Effect of Autoclave Sterilization on Resistance to Cyclic Fatigue of Hero Endodontic File \#642 (6\%) at Two Artificial Curvature. Journal of Dentistry (Shiraz, Iran) 18: 277-281. [crossref]

22. Condorelli GG, Bonaccorso A, Smecca E, Scha"fer E, Cantatore G et al. (2010). Improvement of the fatigue resistance of NiTi endodontic files by surface and bulk modifications. International Endodontic Journal 43: 866-873. [crossref]

23. Mize SB, Clement DJ, Pruett JP, Carnes DL Jr (1998) Effect of sterilization on cyclic fatigue of rotary nickel-titanium endodontic instruments. Journal of Endodontics 24: 843-847. [crossref]

24. Alexandrou GB, Chrissafis K, Vasiliadis LP, Pavlidou E, Polychroniadis EK (2006) SEM observations and differential scanning calorimetric studies of new and sterilized nickeltitanium rotary endodontic instruments. Journal of Endodontics 32: 675-679.

25. Valois CR, Silva LP, Azevedo RB (2008) Multiple autoclave cycles affect the surface of rotary nickel-titanium files: an atomic force microscopy study. Journal of Endodontics 34: 859-862. [crossref]

26. Viana AC, Gonzalez BM, Buono VT, Bahia MG (2006) Influence of sterilization on mechanical properties and fatigue resistance of nickel-titanium rotary endodontic instruments. Int Endod J 39: 709-715. [crossref]

27. Shen Y, Coil JM, Mo AJ, Wang Z, Hieawy A et al. (2016) Wave One Rotary Instruments after Clinical Use. Journal of Endodontics 42: 186-189. [crossref]

28. Tripi TR, Bonaccorso A, Tripi V, Condorelli GG, RapisardaE (2001) Defects in GT rotary instruments after use:an SEM study. Journal of endodontics 27: 782-785. [crossref]

29. Nair AS, Tilakchand M, Naik BD (2015) The effect of multiple autoclave cycles on the surface of rotary nickel-titanium endodontic files: An in vitro atomic force microscopy investigation. J Conserv Dent 18: 218-22. [crossref]

30. Moller AJ, Fabricius L, Dahlen G, Ohman AE, Heyden G (1981) Influence on periapical tissues of indigenous oral bacteria and necrotic pulp tissue in monkeys. Scand J Dent Res 89: 475-484. [crossref]
31. Sundqvist G (1976) Bacteriological studies of necrotic dental pulps. Umeå, Sweden: Umeå University. Dissertation

32. Kumar Kv, Kiran Kumar K, Supreetha S, Raghu K, Veerabhadrappa A et al. (2015) Pathological evaluation for sterilization of routinely used prosthodontic and endodontic instruments. Journal of International Society of Preventive and Community Dentistry 5: 232-236. [crossref]

33. Rutala WA, Weber DJ (2001) Creutzfeldt-Jakob disease: recommendations for disinfection and sterilization. Clin Infect Dis, 32: 1348-1356. [crossref]

34. O'Hoy PY, Messer HH, Palamara JE (2003) The effect of cleaning procedures on fracture properties and corrosion of NiTi files. International Endodontic Journal 36 724-32. [crossref]

35. Novoa XR, Martin-Biedma B, Varela-Patino P (2007) The corrosion of nickeltitanium rotary endodontic instruments in sodium hypochlorite. International Endodontic Journal 40: 36-44. [crossref]

36. Ormiga Galvao Barbosa F, Antonio da Cunha Ponciano Gomes J, Pimenta de Araujo MC (2007) Influence of sodium hypochlorite on mechanical properties of K3 nickeltitanium rotary instruments. Journal of Endodontics 33: 982-985.

37. Cavalleri G, Cantatore G, Costa A, Grillenzoni M, Comin Chiaramonti L et al (2009) The corrosive effects of sodium hypochlorite on nickel-titanium endodontic instruments: assessment by digital scanning microscope. Minerva Stomatologica 58: 225-231. [crossref]

38. Berutti E, Angelini E, Rigolone M, Migliaretti G, Pasqualini D (2006) Influence of sodium hypochlorite on fracture properties and corrosion of ProTaper Rotary instruments. International Endodontic Journal 39: 693-639. [crossref]

39. Peters OA, Roehlike JO, Baumann MA (2007) Effect of immersion in sodium hypochlorite on torque and fatigue resistance of nickel-titanium instruments. Journal of Endodontics 33: 589-593. [crossref]

40. Busslinger A, Sener B, Barbakow F (1998) Effects of sodium hypochlorite on nickeltitanium Lightspeed instruments. International Endodontic Journal 31: 290-294. [crossref]

41. Haikel Y, Serfaty R, Wilson P, Speisser JM, Allemann C (1998) Cutting efficiency of nickel-titanium endodontic instruments and the effect of sodium hypochlorite treatment. Journal of Endodontics 24: 736-739. [crossref]

42. Health \& Medicine Week, "Findings from University of Catania Yields New Data on Hypochlorous Acid (2018) (Cyclic Fatigue Resistance of Heat-treated Nickeltitanium Instruments after Immersion in Sodium Hypochlorite and/or Sterilization 3597.

43. Walia HM, Brantley WA, Gerstein H (1988) An initial investigation of the bending and torsional properties of Nitinol root canal files. Journal of Endodontics 14: 346351. [crossref]

44. Sattapan B, Palamara JE, Messer HH (2000-a) Torque during canal instrumentation using rotary nickel-titanium files. Journal of Endodontics 26: 156-60. [crossref]

45. Sattapan B, Nervo GJ, Palamara JE, Messer HH (2000-b) Defects in rotary nickeltitanium files after clinical use. Journal of Endodontics 26: 161-165. [crossref]

46. Parashos P, Gordon I, Messer HH (2004) Factors influencing defects of rotary nickeltitanium endodontic instruments after clinical use. JOE 30: 722-725. [crossref]

47. Peng B, Shen Y, Cheung GS, Xia TJ (2005) Defects in ProTaper S1 instruments after clinical use: longitudinal examination. IEJ 38: 550-557. [crossref]

48. Cheung G.S.P. (2009) Instrument fracture: mechanisms, removal of fragments, and clinical outcomes. Endodontic Topics 16: 1-26

49. Svec TA, Powers JM (2002) The deterioration of rotary nickel- titanium files under controlled conditions. Journal of Endodontics 28: 105-107.

50. Alapati SB, Brantley WA, Svec TA, Powers JM, Mitchell JC (2003) Scanning electron microscope observations of new and used nickel-titanium rotary files. Journal of Endodontics 29: 667-669. [crossref]

51. Gambarini G (2001) Cyclic fatigue of ProFile rotary instruments after prolonged clinical use. International Endodontic Journal 34: 386-389. [crossref]

52. Dalton BC, Ørstavik D, Phillips C, Pettiette M, Trope M (1998) Bacterial reduction with nickel-titanium rotary instrumentation. Journal of Endodontics, 24: 763-767. [crossref] 
53. Gulabivala K, Stock CJR (2004) Root canal system preparation, In: Stock CJR Gulabivala K, Walker RT, eds. Endodontics 3: 135-172.

54. Scarfe WC, Levin MD, Gane D, Farman AG (2009) Use of cone beam computed tomography in endodontics. International Endodontic Journal 10: 634-638

55. Shuping GB, Ørstavik D, Sigurdsson A, Trope M (2000) Reduction of intracanal bacteria using nickel-titanium rotary instrumentation and various medications. Journal of Endodontics 26: 751-755. [crossref]

56. Spångberg L (2001) The wonderful world of rotary root canal preparation, Oral Surgery Oral Medicine Oral Pathology Oral Radiology and Endodontology, 92: 479. [crossref]

57. Ankrum MT, Hartwell GR, Truitt JE (2004) K3 Endo, ProTaper, and ProFile systems: breakage and distortion in severely curved roots of molars, Journal of Endodontics, 30, 234-237. [crossref]

58. Paqué F, Musch U, Hülsmann M (2005) Comparison of root canal preparation using $\mathrm{RaCe}$ and ProTaper rotary NiTi instruments. International Endodontic Journal 38: 8-16. [crossref]

59. Rangel S, Cremonese R, Bryant S, Dummer P (2005) Shaping ability of RaCe rotary nickel-titanium instruments in simulated root canal. Journal of Endodontics 31: 460-463.
60. Schäfer E, Schlingemann R (2003) Efficiency of rotary nickel-titanium K3 instruments compared with stainless-steel hand K-Flexofile. Part 2. Cleaning effectiveness and instrumentation results in severely curved root canals of extracted teeth. International Endodontic Journal 36: 208-217. [crossref]

61. Schäfer E, Vlassis M (2004) Comparative investigation of two rotary nickeltitanium instruments: ProTaper versus RaCe. Part 2. Cleaning effectiveness and instrumentation results in severely curved root canals of extracted teeth. International Endodontic Journal 37: 239-248. [crossref]

62. Yoshimine Y, Ono M, Akamine A (2005) The shaping effects of three nickeltitanium rotary instruments in simulated S-shaped canals. Journal of Endodontic 31: 373-375. [crossref]

63. Stewart JT, Lafkowitz S, Appelbaum K, Hartwell G (2010) Distortion and breakage of Liberator, EndoSequence, and ProFile systems in severely curved roots of molars. Journal of Endodontic 36: 729-731. [crossref]

64. Di Fiore Di Fiore PM, Genov KA, Komaroff E, Li Y, Lin L (2006) Nickel-Titanium rotary instrument fracture: a clinical practice assessment. International Endodontic Journal 39: 700-708. [crossref]

65. Shen Y, Cheung GS, Bian Z, Peng B (2006) Comparison of defects in ProFile and ProTaper systems after clinical use. JOE 32: 61-65. [crossref]

66. Shen Y, Cheung GS, Peng B, Haapasalo M (2009) Defects in nickel-titanium instruments after clinical use. Part 2: fractographic analysis of fractured surface in a cohort study. JOE 35: 133-136. [crossref]

\section{Citation:}

Reem AlYamoor, Stefan V. Stefanescu, Haider Al-Saffar and Mihai Calin Chirila (2020) A Critical Evaluation of the Single-Use Policy of Endodontic Instruments. J Dent Maxillofacial Res Volume 3(3): 1-5. 